\title{
Media Motion Graphics Untuk Penyampaian Materi "Bagaimana Manusia Memproses Emosi dan Tahapan Perkembangan (Piaget)"
}

\author{
Wiputra Cendana ${ }^{1}$, Nico Tanles Tjhin ${ }^{2}$ \\ Universitas Pelita Harapan \\ wiputra.cendana@gmail.com,nico.tjhin@uph.edu
}

\begin{abstract}
The goal to be achieved in writing Interactive Media and Learning paper is to make interactive learning design of human emotions and stages of human cognitive development based on a theory by Jean Piaget. This was motivated by the repetition of the same material by lecturers to more than 40 students. The university is the highest peak in the formal education level applied in Indonesia, which is taken for 3.5 - 4 years. Students' diverse backgrounds and cognitive skills make them have to keep trying to absorb the content from the lectures. Multimedia Interactive is a media that consists of many components or media that are connected to each other and are able to interact. Teaching media in the form of interactive multimedia has the ability to store audio-visual data, making interactive multimedia especially interactive learning as a supporter of conventional learning methods that were delivered through books and direct explanations without examples are considered to be less easily digested by students, so it is hoped that the use of interactive power point media aims to increase the absorption of material by students who are able to provide information more interesting and enjoyable than just listening to the one-time delivery of material by supporting lecturers.
\end{abstract}

Keywords: Emotion, Cognitive Development Stage, Higher Education, Interactive Learning

\begin{abstract}
Abstrak
Tujuan yang ingin dicapai dalam penulisan Media Interaktif dan Pembelajaran ini adalah membuat interaktif pembelajaran emosi manusia dan tahapan perkembangan kognitif manusia berdasarkan teori yang dikemukan oleh Jean Piaget. Hal ini dilatar belakangi oleh pengulangan materi yang sama oleh dosen pengampu kepada mahasiswa yang berjumlah lebih dari 40 mahasiswa. Universitas adalah puncak tertinggi dalam jenjang pendidikan formal yang diterapkan di Indonesia yang ditempuh selama 3.5 - 4 tahun. Latar belakang dan kognitif mahasiswa yang beragam membuat mereka harus terus berusaha menyerap perkuliahan yang ada. Multimedia Interaktif adalah suatu media yang terdiri dari banyak komponen atau media yang terhubung satu sama lain dan mampu berinteraksi. Pengajaran media dalam bentuk multimedia interaktif memiliki kemampuan untuk menyimpan audio visual data, membuat multimedia interaktif khususnya interaktif pembelajaran sebagai pendukung metode pembelajaran konvensional yang dulu disampaikan melalui buku dan penjelasan langsung tanpa contoh dianggap kurang mudah dicerna oleh mahasiswa, sehingga diharapkan pemanfaatan media power point interaktif yang bertujuan untuk meningkatkan penyerapan materi oleh mahasiswa yang mampu
\end{abstract}


memberikan informasi dengan lebih menarik dan menyenangkan dari pada hanya mendengarkan satu kali penyampaian materi oleh dosen pengampu.

Kata Kunci: Emosi, Tahap Perkembangan Kognitif, Pendidikan Tinggi, Pembelajaran Interaktif

\section{PENDAHULUAN}

Semua manusia memiliki emosi dan selalu berurusan dengan emosi dalam kesehariannya. Emosi tidak muncul begitu saja, melainkan terdapat rangkaian proses yang akhirnya muncul emosi dalam diri seseorang (Sincero, 2012). Ada jenis emosi yang positif seperti bahagia, damai, serta bersyukur, dan ada juga jenis emosi negatif seperti sedih, marah, kesal, kecewa, serta benci. Emosi-emosi seperti ini terkadang tidak terlalu mudah untuk dipahami. Apabila seseorang gagal memahaminya, maka dirinya bisa menjadi frustrasi dan gagal untuk berkembang dengan ideal.

Dalam konteks belajar mengajar di dalam kelas, penting bagi pada proyek ini adalah milik Jean Piaget. Semakin banyak memahami teori perkembangan kognitif, maka kita akan semakin mengerti apa yang terjadi ketika emosi anak didik kita bergejolak. Proses emosi seseorang tidak terpisah dari proses kognitifnya. Mahasiswa akan dibantu dengan pemaparan studi kasus yang juga akan dipresentasikan melalui video interaktif. Tujuan dari proyek ini adalah membuat media motion graphics dan video interaktif untuk menyampaikan materi bagaimana manusia memproses emosi serta bagaimana perkembangan kognisi para guru untuk memahami emosi mereka sendiri. Untuk dapat menangani emosi yang bergejolak dari murid yang ditangani, seorang guru perlu terlebih dahulu mengenali emosi, baik positif maupun negatif, yang timbul dari dalam diri murid. Agar mampu mengenali emosi tersebut, seorang individu perlu mempelajari bagaimana dan dari mana emosi itu muncul. Untuk mempelajari hal ini tidaklah mudah bagi kebanyakan orang karena emosi beserta proses dan implikasinya bersifat abstrak. Setelah mampu memahami emosi diri, perlu adanya pembelajaran teori perkembangan kognitif.

Teori perkembangan kognitif
dipakai
yang $\begin{array}{r}\text { orang. } \\ \text { terjadi pada kebanyakan ora }\end{array}$
Sesuatu yang abstrak akan jauh lebih mudah dipahami ketika penjelasannya divisualisasikan secara menarik melalui teknik pembuatan motion graphics dan video interaktif yang baik. Harapannya setiap calon guru yang dipersiapkan dapat memahami bagaimana proses pembentukan emosi terjadi dan proses perkembangan kognitif pada anak terjadi sehingga mereka dapat menangani emosi, baik emosi diri mereka maupun emosi dari murid mereka, dengan baik. 
Fokus dari proyek ini adalah membuat para calon guru paham seutuhnya akan bagaimana manusia memproses emosi dan bagaimana manusia pada umumnya secara kognitif berkembang, dimana akan dinilai menggunakan alat ukur berupa pembuatan mind mapping pada akhir dari penyampaian materi. Namun proyek ini tidak memfasilitasi mereka untuk berlatih secara praktek menangani emosi mereka dan emosi orang lain. Sehingga diharapkan adanya upaya tindak lanjut dari mereka dalam berlatih menangani emosi secara praktek di luar kelas agar mengalami manfaat yang utuh. Proyek ini akan diterapkan kepada 43 mahasiswa Teachers College Universitas Pelita Harapan, di dalam kelas mata kuliah Psikologi Perkembangan.

\section{METODE PENELITIAN}

Prinsip serta proses
pembuatan media motion graphics
dan video interaktif ini merujuk pada
beberapa teori yang ada. Teori-teori
ini dapat dibagi ke dalam dua bagian,
yaitu teori utama dan teori
pendukung:

\section{Teori Utama}

a. Technology and Curriculum Integration (Shelly \& Cashman, 2006)

Integrasi teknologi atau integrasi kurikulum adalah penggabungan antara seluruh bagian teknologi, baik perangkat keras maupun perangkat lunak, dengan setiap mata pelajaran di dalam kurikulum agar menciptakan pembelajaran yang lebih optimal. Dengan kata lain, integrasi teknologi adalah penggunaan teknologi untuk mencapai standar kurikulum dan hasil pembelajaran dari setiap mata pelajaran, unit, atau kegiatan. Kunci dari keberhasilan akan integrasi teknologi adalah dengan mengidentifikasikan apa yang ingin dicapai di dalam kurikulum. Guru juga harus memperhatikan apa yang menjadi standar dan acuan kurikulum yang diterapkan, mengidentifikasi teknologi yang cocok, dan mengembangkan cara-cara inovatif dalam mengajar populasi pelajar yang beragam dengan gaya pembelajarannya masing-masing.

b. Changing Instructional Strategies (Shelly \& Cashman, 2006)

Sesuai dengan perkembangan, murid memainkan peran yang lebih aktif dalam pembelajaran. Maka peran guru seharusnya juga menyesuaikan akan hal ini. Guru bertransisi dari mempraktekkan metode mengajar konvensional kepada metode fasilitasi dalam pembelajaran. Seorang fasilitator dalam pembelajaran tidak seharusnya mendikte proses pembelejaran, melainkan memotivasi 


\section{Cendana \& Tjhin}

muridnya untuk belajar, membimbing proses pembelajaran murid, dan membangun atmosfer pembelajaran dan apresiasi terhadap mata pelajaran yang diajarkan.

c. Multimedia

Authoring

Software (Shelly \& Cashman, 2006)

Multimedia

Authoring

Software dipakai untuk menciptakan sebuah presentasi elektronik yang melibatkan teks, grafik, video, audio, dan animasi. Software ini dapat membantu mencipatakan sebuah presentasi dengan memberikan kebebasan bagi pengguna untuk meletakkan teks dan grafik, serta durasi suara, video dan animasi. Setelah dibuat, presentasi multimedia tersebut biasanya akan memainkan peran sebagai presentasi computerbased yang interaktif, dirancang untuk memfasilitasi pembelajaran dan memperoleh partisipasi langsung dari murid.

d. Hypermedia (Sharp, 2005)

Hampir serupa dengan hyperteks, hypermedia menekankan pada komponen yang bersifat nontekstual dari hyperteks. Hypermedia memakai komputer untuk memasukkan, memanipulasi, dan menghasilkan grafik, suara, teks, dan video sebagai bagian dari sebuah sistem. Bentuk-bentuk informasi yang berbeda dihubungkan satu sama lain. Dalam penggabungan ini, guru perlu menggunakan berbagai jenis perlengkapan yang berbedabeda seperti video kamera, voice recorder, scanner, musical keyboard, speaker, microphone, LCD, dan lainlain.

e. Motion Graphics (Fattahi, 2014)

Motion Graphics dapat disebut sebagai sebuah ilmu yang mengkombinasikan gerakan dan suara di media. Semakin berkembangnya jaman, Motion Graphics digunakan dalam pembuatan karya novel melalui gambar yang bergerak atau design vektor dengan menambahkan suara ke dalamnya. Motion Graphics saat ini telah dianggap sebagai alat yang efektif dalam mengekspresikan visualisasi.

f. Learning Style (Chick, 2017) Isitlah ini dipakai untuk menjelaskan bagaimana pembelajar mengumpulkan, menyaring, mengintepretasi, mengorganisasi,

menyimpulkan, dan menyimpan informasi untuk diolah lebih jauh. Setiap pembelajar memiliki gayanya atau preferensinya sendiri dalam melakukan semua hal ini. Secara umum terdapat 


$$
\begin{aligned}
& \text { empat jenis gaya } \\
& \text { pembelajaran. Namun motion } \\
& \text { graphics menjawab tiga gaya } \\
& \text { pembelajaran dalam } \\
& \text { penyampaian materi, yaitu: }
\end{aligned}
$$

\section{Teori Pendukung}

a. Distributable

Materi motion graphics dapat dibagikan kepada mahasiswa dan diakses dengan bebas oleh mereka melalui gadget masing-masing, sehingga materi dapat dimainkan berulang-ulang kapanpun dimanapun untuk dipelajari dengan baik.

b. Color

Pemilihan warna dalam motion graphics dipilih dan digunakan secara konsisten agar otak lebih mudah memproses, menghafal, dan mengolah informasi yang disampaikan melalui visualisasi ilustrasi. Warna yang dipilih adalah hitam, putih, hot pink dan turquoise blue.

\section{c. Narrative}

Penjelasan dipresentasikan dengan alur narasi menggunakan bahasa seharihari agar mahasiswa lebih mudah mengikuti alur penjelasannya dan menangkap bagian demi bagian dari narasi tersebut yang akhirnya mendapatkan pemahaman yang utuh dari materi yang disampaikan.

\section{HASIL DAN PEMBAHASAN}

Setelah media pembelajaran ditayangkan, penulis menginstruksikan mahasiswa untuk menuliskan suatu tulisan yang berisi cakupan dari topik yang sudah disampaikan. Mahasiswa diberikan ruang kreativitas untuk menuangkan setiap dari apa yang sudah dilihat, didengar, dan dirasakan dari penyampaian mata kuliah Psikologi Perkembangan oleh penulis. Rubrik penilaian sudah ditetapkan oleh penulis di awal dengan skala 1 - 4 . Kriteria penilaian berdasarkan kepada aspek pengetahuan dan pemahaman mahasiswa. Hasil perolehan nilai akhir dari penilaian adalah sbb.

Tabel. 1. Hasil Perolehan Nilai Akhir

\begin{tabular}{cccc}
\hline No & Nilai & Jumlah & Persentase \\
\hline 1 & 2.5 & 1 & $6 \%$ \\
2 & 5 & 2 & $12 \%$ \\
3 & 6.25 & 9 & $16 \%$ \\
4 & 7.5 & 13 & $19 \%$ \\
5 & 8.75 & 8 & $22 \%$ \\
6 & 10 & 10 & $25 \%$ \\
\hline & Total & 43 & $100 \%$ \\
\hline
\end{tabular}


Tabel di atas menunjukkan adanya perbandingan lurus antara perolehan nilai mahasiswa dan presentase dari jumlah mahasiswa yang mendapatkan nilai tersebut.

Melalui hasil didapatkan perolehan persentase tingkat pemahaman daripada penyerapan materi yang diberikan cukup baik (terdapat perolehan nilai >6.25 sebesar 83\%). Mahasiswa mendapatkan suatu pengalaman pembelajaran yang berbeda dari sebelumnya. Penggunaan media pias kata yang merupakan media visual terbukti memberikan pengaruh yang efektif pada kemampuan membaca nyaring pada siswa seperti dikutip dari Jurnal Trapsila (Putri, 2019). Metode ceramah di dalam kelas tatap muka dapat didesain kembali melalui media power point integratif dengan melakukan perekaman dosen pengampu yang menjelaskan materi tersebut. Dalam hal ini, metode yang dipakai dapat berlanjut kepada Program Pendidikan Jarak Jauh atau blended learning. Harapannya adalah mahasiswa semakin menggunakan penggunaan teknologi media semakin baik dan sesuai dengan kebutuhan masing-masing mahasiswa. Dosen pengampu juga dapat bersumbangsih untuk memberikan kesempatan mahasiswa mengeksplorasi topik pembelajaran yang disesuaikan dengan ekspektasi dari capaian pembelajaran.

\section{SIMPULAN}

Kesimpulan dari pembuatan materi ajar interaktif ini adalah teknologi yang terus berkembang sangat berpengaruh terhadap cara mahasiswa menyerap pembelajaran. Inovasi teknologi yang dipersiapkan secara matang oleh dosen pengampu dari mata kuliah dapat memberikan sensasi penyampaian materi ke arah yang lebih baik sesuai dengan analisis kebutuhan dari mahasiswa itu sendiri dan capaian pembelajaran yang diharapkan.

Saran yang dapat diberikan adalah power point yang digunakan dalam presentasi sebaiknya berupa poin-poin utama ataupun gambargambar visualisasi. Hal ini untuk mengurangi tingkat kebosanan mahasiswa terhadap penulisan teks yang panjang dalam media power point tersebut. Selain itu, kontras warna latar dan tulisan dalam media power point sangat berpengaruh terhadap tampilan dari power point itu sendiri.

\section{DAFTAR RUJUKAN}

Chick, N. (2017). Center for Teaching: Learning Styles. Retrieved Sep 14, 2017 from cft.vanderbilt.edu:

https://cft.vanderbilt.edu/guide s-sub-pages/learning-stylespreferences/

Fattahi, M. (2014). The Position of Motion Graphic in Communication Media. Indian J.Sci.Res. 7 (1): 815-819. Pg. 1.

Heinich, R. dkk., (1996). Instructional Media and 
Technology for Learning.

New Jersey: Prentice Hall,

Inc.

Putri, L. (2019) Peningkatan

Keterampilan Membaca

Nyaring melalui Media Pias-

Pias Kata Pada Siswa Kelas I

SDN 1 Mojorejo Ponorogo.

Trapsila: Jurnal Pendidikan

Dasar.

DOI:

http://dx.doi.org/10.30742/tpd. $\underline{\mathrm{v} 1 \mathrm{i} 01.726}$

Sarah Mae Sincero (Nov 26, 2012).

James-Lange Theory of

Emotion. Retrieved Sep 10,

2017 from Explorable.com:

https://explorable.com/james-

lange-theory-of-emotion

Sharp, V. (2005). Computer Education for Teachers: Integrating Technology into Classroom Teaching. 5th Edition. New York: The McGraw-Hill Companies. Pg. 172-173.

Shelly, G. B. \& Cashman, T. J. (2006). Teachers Discovering Computers: Integrating Technology and Digital Media in the Classroom. 4th Edition. Boston: Thomson Course Technology. Pg. 167, 366. 